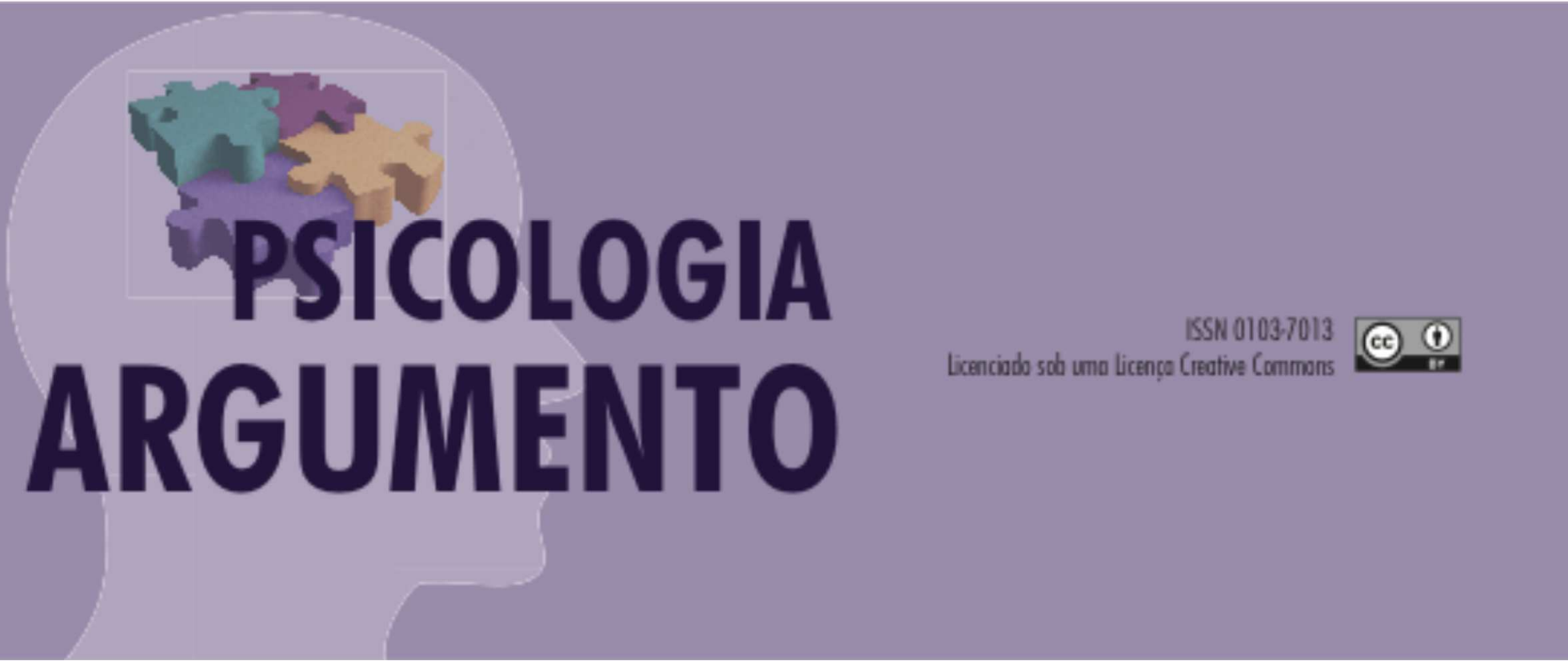

doi: http://dx.doi.org/10.7213/psicolargum.35.90.22205

\title{
A psicopatologia na perspectiva de Carl Gustav Jung
}

\author{
Psychopathology in the perspective of Carl Gustav Jung
}

\begin{abstract}
Elisângela Sousa Pimenta de Padua
Psicóloga clínica, mestre em Psicologia Clínica (UFPR). Avenida Marechal Deodoro, 1269, bloco 6 , apto.4, Curitiba/PR, CEP: 80060-010. Fone: 41 - 995423174, Email: elis.padua@yahoo.com.br.

Carlos Augusto Serbena

Psicólogo, mestre em Psicologia e Sociedade (UFSC), doutor em Ciências Humanas (UFSC). Docente da Universidade Federal do Paraná - Praça Santos Andrade | $2^{\circ}$ andar | Curitiba - PR, CEP: 80060-010. Fone: 41 - 99191-6886, E-mail:

caserbena@gmail.com
\end{abstract}

\section{Resumo}

A psiquiatria psicodinâmica, normalmente associada à psicanálise, possui diversas abordagens teóricas dissidentes desta. Dentre elas, a mais expressiva é a Psicologia Analítica desenvolvida pelo psiquiatra suíço Carl Gustav Jung, cuja hipótese fundamental é o inconsciente coletivo. Isto possibilitou elaborar uma perspectiva psicogênica, simbólica e hermenêutica dos fenômenos psíquicos. Assim, o objetivo desta pesquisa é identificar as principais ideias, teorias e conceitos a respeito das psicopatologias segundo este autor. Para tal foi realizada uma pesquisa de levantamento bibliográfico das suas principais obras relacionadas ao tema. Foi possível delimitar dez critérios referentes às suas principais ideias e teorias. A partir destas constatações, conclui-se que as psicopatologias possuem sentido, significado e finalidade quando compreendidas simbolicamente e fazem parte do processo de individuação.

Palavras-Chave: Psicologia Analítica; Psicopatologia; Adoecimento Psíquico. 


\begin{abstract}
Psychodynamic psychiatry, usually associated with psychoanalysis, has several dissenting theoretical approaches. Among them, the most expressive is the Analytic Psychology developed by the swiss psychiatrist Carl Gustav Jung, whose fundamental hypothesis is the collective unconscious. This allowed to elaborate a psychogenic, symbolic and hermeneutic perspective of the psychic phenomena. Thus, the objective of this research is to identify the main ideas, theories and concepts regarding psychopathologies according to this author. For this, a bibliographical survey of his main works related to the theme was carried out. It was possible to delimit ten criteria referring to its main ideas and theories. From these findings, we conclude that the psychopathologies have sense, meaning and purpose when comprehended symbolically and are part of the process of individuation.
\end{abstract}

Keywords: Analytical Psychology; Psychopathology; Psychic Illness.

\title{
Resumen
}

Lorem ipsum dolor sit amet, consectetur adipiscing elit. Sed id dictum tortor, et viverra nisi. Sed dolor nibh, vulputate vel enim sed, hendrerit malesuada risus. Fusce sit amet dignissim purus, pellentesque aliquam purus. Morbi vel nisi urna. Praesent molestie arcu arcu, egestas facilisis tortor consequat semper. Quisque pharetra urna eros, non laoreet tortor elementum ac

Palabras clave: Predictores del TEPT en niños; apoyo social y TEPT; grado de exposición y TEPT

\section{Introdução}

Atualmente, sob a perspectiva psiquiátrica geral, a psicopatologia é compreendida como um campo de conhecimento que se utiliza do rigor da ciência sensu strictu para sistematizar e descrever os elementos que compõem o fenômeno do adoecimento mental. A sistematização da psicopatologia possibilita apreender em conceitos os fenômenos psicopatológicos (por exemplo: depressão, esquizofrenia, compulsão) e favorecer a comunicação entre profissionais. A conceituação das psicopatologias não alcança a compreensão total das vivências psicopatológicas humanas, o que possibilitou divergências, contradições e lacunas teóricas neste campo de conhecimento. (Delgalarrondo, 2008, p.28).

O presente artigo tem por tema a psicopatologia na perspectiva psicológica do médico psiquiatra suíço Carl Gustav Jung (1875-1961). Este foi um crítico do posicionamento classificatório da psiquiatria clássica. Ele se localiza historicamente como médico psiquiatra pertencente da Era Psicodinâmica ou Psiquiatria Moderna. O paradigma psicodinâmico tem o "inconsciente" como hipótese e compreende as etiologias das psicopatologias como psicogênicas, ou seja, há interferência da afetividade, das relações interpessoais, da história de vida, dos fatores inconscientes para além das concepções organogênicas, características da Psiquiatria Clássica. (Ellemberger, 1976, p.137; Martinez, 2006, p.90). 
Influenciado pelo paradigma psicogênico das doenças mentais, Jung participa, na primeira década do século $X X$, das pesquisas experimentais e dos estudos práticos e teóricos da psicanálise ao lado de Sigmund Freud (1856-1939) e Eugen Bleuler (1857-1939). Avança nos estudos da esquizofrenia, fundamenta o conceito de complexos ideo-afetivos com base no método experimental, seguido pelo método psicanalítico, porém por divergências teóricas separa-se da Sociedade de Psicanálise, fundamentando sua própria abordagem da psique: a Psicologia Analítica, cuja hipótese é o inconsciente coletivo. (Ellemberger, 1976).

Desta forma, objetivo é identificar quais ideias centrais desenvolvidas pelo autor para compreender os fenômenos psicopatológicos. Também busca identificar de que modo sua teoria adquire uma perspectiva simbólica, psicogênica e finalista (teleológica) dos adoecimentos mentais. E, finalmente, apontar quais são as possíveis perspectivas encontradas atualmente no campo teórico da Psicologia Analítica que favorecem uma visão multifacetada desses fenômenos.

\section{A Perspectiva Psicogênica e Hermenêutica das Psicopatologias}

Para Jung (2012a), os médicos psiquiatras deveriam, em sua formação profissional, estudar psicologia, filosofia, história da humanidade e outras matérias humanas, não se restringindo apenas aos estudos anátomo-fisiológicos. As disciplinas humanas possibilitam maior compreensão do adoecimento mental, posto que refletem sobre a alma humana, o seu contexto e historicidade. (§297).

A psique não é uma coisa dada, imutável, mas um produto de sua história em marcha. Assim, não só secreções glandulares alteradas ou relações pessoais difíceis são as causas de conflitos neuróticos; entram em jogo também, em igual proporção, tendências e conteúdos decorrentes da história do espírito. Conhecimentos bio-médicos previamente são insuficientes para compreender a natureza da alma. O entendimento psiquiátrico do processo patológico de modo algum possibilita o seu enquadramento no âmbito geral da psique. Da mesma forma, a simples racionalização é um instrumento insuficiente. A história sempre de novo nos ensina que, ao contrário da expectativa racional, fatores assim chamados irracionais exercem o papel principal, e mesmo decisivo, em todos os processos de transformação da alma. (Jung, 2013, p.17).

Para ele, o problema da alma vai além do viés fisiológico e psiquiátrico, pois é ela um território em si, com leis próprias, diferente das leis fisiológicas. Assim, o empreendimento de Jung (2012a) como pesquisador da alma humana é identificar as leis inerentes de tais processos, a natureza particular da psique, diferenciandoa do aparato cerebral, hormonal, fisiológico, etc. Mas, reconhece que ambos, psique e corpo, estão inter-relacionadas e formam uma unidade dinâmica.

Não se trata de negar a influência dos fatores orgânicos nas etiologias das doenças mentais, mas sim, sugerir um olhar psicológico para estes fenômenos. A psicogênese das doenças mentais implica em reconhecer que a causa das neuroses ou das psicoses, ou as condições que favorecem seu aparecimento, 
"(...)é de natureza psíquica. Pode ser um choque psíquico, um conflito desgastante, uma adaptação psíquica errônea ou uma ilusão fatal”. (Jung, 2012c, §496). Em outras palavras, o paradigma psicodinâmico consiste em enfatizar a afetividade como causa do desequilíbrio "na regulação, direção e perturbação da vida psíquica". (Martinez, 2006, p.94).

Nesta perspectiva, a compreensão das psicopatologias implica em conhecer a história e as experiências individuais, ou seja, conhecer o conteúdo dos complexos. Estes são os conteúdos oriundos das experiências pessoais, que jamais se assemelharão por completo a outro ser humano, portanto, o tratamento de uma psicopatologia é individual, de acordo com a necessidade do paciente. "Seu objeto não é a fixação de uma neurose, mas sim a perturbação da integridade de uma pessoa". (Jung, 2012c, §199).

Os complexos são conteúdos ideo-afetivos assimilados em torno de um núcleo arquetípico que possibilita um padrão geral de comportamento, instinto, emoções, tema de sofrimento e conflito psíquico "típico" e "geral", acometendo todos humanos em sua forma, mas o conteúdo a ser elaborado é sempre de ordem pessoal. Esta especificidade coletiva é o que possibilita estabelecer classificações e tipos gerais de adoecimentos psicológicos.

Identificar o sentido do conteúdo dos complexos e arquétipos constelados é a finalidade do método hermenêutico sintético ou construtivo desenvolvido por Jung (2014, p.92). Trata-se de uma técnica que facilita a transcendência do conflito de opostos (consciente e inconsciente). Favorece uma transformação da consciência na medida em que facilita a compreensão dos conteúdos inconscientes por meio de analogia de temas mitológicos, religiosos, coletivos, aproximando sentidos e significados que estavam inconscientes. Por meio dele não se alcança as causas dos fenômenos psicológicos, mas visualiza-se o sentido e a finalidade que favorece o desenvolvimento psíquico, portanto, é concebido por Jung como teleológico, e não causalista.

Isto significa que os sintomas e as doenças mentais podem ser entendidos como símbolos que apontam para uma finalidade, para um desenvolvimento. Jung compreende os símbolos como elementos que formam uma totalidade unindo polaridades consciente e inconsciente ou fatores heterogêneos e contraditórios que estão em conflito visando uma superação transcendente da situação conflituosa, de modo a integrar (não reprimir e favorecer apenas um aspecto do conflito) e possibilitar uma nova consciência, uma nova perspectiva. Para Jung (2013), o símbolo é "(...) uma imagem de um conteúdo em sua maior parte transcendental ao consciente. É necessário descobrir que tais conteúdos são reais, são agentes com os quais um entendimento não só é possível, mas necessário". (§114).

\section{Revisão Bibliográfica das Perspectivas Teóricas da Psicopatologia em Carl Gustav Jung}


Algumas ideias sobre o adoecimento psíquico na perspectiva de Jung foram levantadas por autores de grande relevância no campo da Psicologia Analítica, indo de encontro com o objetivo deste artigo. Para Samuels (1989), Jung atribui as psicopatologias ao ego e elabora um quadro sobre "Psicopatologia do Ego" (p.86) com sete critérios possíveis. Segue uma descrição resumida das constatações do autor:

$1^{\circ}$ o ego não emerge satisfatoriamente de sua unidade com o self, havendo pouca discriminação e consciência;

$2^{\circ}$ o eu encontra-se inflacionado devido a uma identificação com o self, renegando outros complexos, aspectos da personalidade e por isto, estes podem gerar tensão e ter consequências destrutivas;

3o ou se identifica com uma atitude extrema e nega sua capacidade mediadora, as outras possibilidades são negligenciadas e desvalorizadas, selecionando apenas o que convém.

$4^{\circ}$ eu não consegue se relacionar com outros complexos de modo imaginativo, criativo e com alteridade;

$5^{\mathrm{a}}$ o eu é subjugado por um aspecto inconsciente;

60 há uma fragilidade na unidade e incapacidade de integração do individuo, de maneira que se fragmenta e acessa facilmente os estados primitivos do psiquismo;

$7^{a}$ quando a função inferior da tipologia junguiana está pouco integrada e não consegue construir sentidos e ter funcionalidade no psiquismo.

Hart (2002), também demonstra que o ego tem papel central nos adoecimentos psíquicos, pois ele é indispensável no processo de tornar consciente os conteúdos inconscientes e progressivamente libertar-se de uma condição alienante de falta de sentido e significado e do estado de compulsão e inflação, ou seja, um estado psicopatológico. É o ego quem media o processo de integração, da mesma forma que é ele quem adoece pela sua incapacidade para tal função.

Fierz (2007) demonstra que nas psicopatologias há um "desequilíbrio psíquico" (p.228) devido a uma relação mal estabelecida entre consciente e inconsciente, quando um se sobrepõe ao outro. Sendo que o ideal é que ambos coexistam, se relacionem com alteridade e tenham igual valor no dinamismo psicológico, estabelecendo o "equilíbrio" que equivale a noção de saúde mental.

Himiob (2006, p.221) demonstra que para Jung o adoecimento neurótico é quando o indivíduo nega e se aparta do contato com os conteúdos do inconsciente, pela Restauração Regressiva da Persona ou aceita tais conteúdos (em casos mais graves pode ser uma psicose, havendo gradações) por meio da Identificação com a psique coletiva.

\section{Metodologia}

Para Clarke (1993, p.41) e Shandasami (2011, p.32), Jung era avesso a sistematização de suas ideias, pois sua perspectiva sobre a psique é de grande 
complexidade e multiplicidades de perspectivas. Foi alvo de críticas devido a falta de unidade geral do pensamento e de uma linha de raciocínio coerente. Sua compreensão é global, muitas vezes contraditória, pois busca muitos caminhos, ideias e métodos de diversas áreas do conhecimento para resolver suas questões. Para ele, a exploração da psique é aberta, com diversas possibilidades e sem soluções definitivas.

Dada complexidade, não é possível identificar uma definição clara e sistematizada do conceito de psicopatologia para Jung, embora seja um tema que atravesse toda sua obra. Entretanto, segundo Clarke (1993), é possível fazer uma investigação semelhante ao método "andar à roda" de Jung, a amplificação, em torno de uma ideia central: a psicopatologia. Através desta investigação, não se busca fechar um conceito ou definir teorias, e sim obter uma visão ampliada do fenômeno (psicopatologia), tornando seu significado mais explícito dentro de sua obra.

Foi realizada uma pesquisa de levantamento bibliográfica nas obras que possibilitam melhor compreensão dos fenômenos psicopatológicos de Carl Gustav Jung. Sabe-se que Jung debruçou-se sobre diversos temas, desde a psiquiatria, religião, alquimia, fenômenos culturais entre outros. Neste trabalho, as obras selecionadas tem um enfoque sobre os escritos de caráter psiquiátrico voltado para os processos da alma humana em diálogo com a Psicologia Clínica e as Psicopatologias. São elas: "A psicogênese das doenças mentais" (2012c), "Símbolos da transformação" (2013), "Tipos psicológicos" (2012f), "Psicologia do inconsciente" (2014), "O eu e o inconsciente" (2012d), "A natureza da psique" (2012a), "Arquétipos e Inconsciente Coletivo" (2012e), "A prática da psicoterapia" (2012b).

Como procedimento, foram pesquisadas nos índices gerais de cada obra as palavras chaves "psicopatologia", "doenças mentais", "neurose", "psicose", "sintomas", "sofrimento psíquicos" e semelhantes e, em seguida foi realizada uma leitura do capítulo e contexto da citação.

A partir da leitura e análise do contexto de cada citação, foram identificadas algumas ideias que se fazem presentes repetidamente ao longo da obra do autor sobre as psicopatologias. São ideias que se inter-relacionam possibilitando maior compreensão e discernimento dos fenômenos psicopatológicos dentro do campo teórico da Psicologia Analítica.

\section{Resultados e Discussões}

Neste tópico serão apresentadas as principais ideias encontradas nas teorias de Carl Gustav Jung com suas devidas discussões e definições a respeito de cada. As discussões são norteadas com referência no próprio autor, de maneira a permanecer fiel a premissa de levantamento bibliográfico. As ideias principais encontram-se destacadas em itálico.

De modo geral as Psicopatologias podem ser compreendidas como compensação da postura unilateral do ego-consciência. Esta perspectiva 
apresentada por Jung (2012c) em seu artigo "A importância do inconsciente na psicopatologia" (p.185), ainda em 1914, prevalece até 1958, em seu artigo "A função transcendente" (2012a , p.IX). Ele defende que é função do inconsciente estabelecer uma relação de compensação com a consciência, podendo muitas vezes se opor ou complementá-la. Para ele, o inconsciente corresponde a processos psíquicos e fisiológicos não percebidos pela consciência e o lado desconhecido da personalidade. Em pessoas normais, o inconsciente compensa a postura consciente promovendo o equilíbrio psíquico, energia vital,insight, desejos, entre outros. Já em casos "anormais", psicopatológicos, a atividade compensatória inconsciente produz sintomas psicogênicos.

Ele compreende que a consciência é um dado recente da espécie humana e favorece o pensamento lógico, linear, racional, focado e discriminativo. Foi o desenvolvimento da consciência que favoreceu a complexidade das civilizações, da técnica, da ciência, da filosofia. Pressupõe-se no uso da consciência "a persistência, regularidade e intencionalidade fidedigna do processo psíquico" (Jung, 2012a, §135) para que haja um bom trabalho, relações estáveis, vida adaptada. Falta tal foco ao pensamento dos primitivos, dos indivíduos adoecidos, das crianças, pois o limiar da consciência é mais vulnerável, sendo esta mais facilmente invadida por conteúdos do inconsciente (afetos, fantasias, desejos, abstrações, etc). A desvantagem é que, se por um lado, para a melhor adaptação, a consciência seleciona os conteúdos que considera compatível a seu senso de realidade/racionalidade, então, por outro lado, ela reprime, ou simplesmente não consegue integrar aqueles conteúdos que possuem características contraditórias, imorais, aparentemente sem sentido, entre outros, ficando relegados ao campo do inconsciente. Este é um processo de inibição, que possui finalidades adaptativas. Isto faz com que a consciência torne-se enrijecida em seu posicionamento, ou seja, unilateral, pois a racionalidade da consciência é preconceituosa, julga ser racional apenas o que the parece racional. $O$ adoecimento ocorre quando esta postura unilateral do ego-consciência não é mais apta a realidade interna e externa do indivíduo.

Para Jung (2012c), no processo de adoecimentos psíquico pode ocorrer uma transformação subjetiva da personalidade devido a perda das funções volitivas do ego, fenômeno descrito inicialmente por Pierre Janet, denominado abaissement du niveau mental, que é predominante nas psicopatologias, desde as neuroses em seu nível normal e controlável, como nas psicoses em nível grave. Trata-se do estreitamento da consciência e redução da atenção.

O "abaissement":

1) Provoca a perda de áreas completas de conteúdos, normalmente controlados;

2) Provoca fragmentação da personalidade; 
3) Impede que sequencias normais de pensamentos se processem de modo coerente e se completem;

4) Restringe a responsabilidade e a reação adequada do eu;

5) Provoca ideias incompletas da realidade, permitindo então o aparecimento de reações emocionais insuficientes e inadequadas;

6) Reduz o limiar da consciência e permite a entrada de conteúdos inconscientes que, em geral, estariam reprimidos, passando a penetrar na consciência sob a forma de invasões autônomas.(Jung, 2012c, §510).

Este fenômeno favorece a diminuição do controle do eu e da consciência (perda da força de vontade, autonomia dos afetos e pensamentos, diminuição da atenção, concentração, memória, etc), e possibilita que conteúdos inconscientes, denominados complexos ideo-afetivos, venham a consciência. $O$ que vai diferenciar a psicose de uma neurose é que na neurose existe uma preservação da unidade central (o eu). Os complexos que estão dissociados da consciência possuem uma autonomia relativizada em relação à consciência, enquanto que na psicose esta relação dos complexos inconscientes está rompida, sendo eles independentes e autônomos em relação à consciência. A psicose não se faz pela sua irracionalidade e estranhamento dos conteúdos, mas pela falta de suporte do "eu" para resistir integralmente a eles. (Jung, 2012c).

No fenômeno de abaissement pode ser observado uma "baixa tensão energética" na consciência: fragmentos de ideias sem continuidade lógica, "formação de analogias, associações superficiais de natureza verbal, sonora ou visual, contaminações, irracionalidade, confusão." (Jung, 2012a, §152). Para ele, trata-se de uma diminuição da personalidade. Descreve como fenômeno de morosidade e depressão, a pessoa sente-se carregada, pesada, indisposta psíquica e fisicamente, sem energia disponível. Se agravar pode levar ao ponto da personalidade perder suas características naturais "desaparecendo a unidade da consciência; as partes isoladas da personalidade tornam-se autônomas e através disso perde-se o controle da consciência" (Jung, 2012e, §213). A personalidade encontra-se limitada, sem auto confiança, ensimesmada, e se desenvolve a partir daí negativamente, sendo assim "representa uma falsificação em relação à personalidade originária". (Jung, 2012e, §214). Segundo Fierz (2007, p.177), o abaissement é um fenômeno característico do estado pré-agudo da psicose aguda, mas não se restringe apenas a estes tipos de caso.

O contato do inconsciente com a consciência ou, em outras palavras, a emergência de complexos inconscientes pessoais e coletivos (arquetípicos) na consciência provocam alterações nesta. Jung denomina como inflação psíquica, pois, para Jung, o material individual é também composto pelo material coletivo. A assimilação da consciência com o material coletivo leva à perda dos limites 
individuais da personalidade, A experiência da inflação psíquica é de que o eu adquiriu conhecimentos e características que não são suas, e sim da coletividade, acredita ser maior ou menor do que realmente é. (Jung, 2012d, p.14). Como exemplo, a identificação do eu com o papel social de juiz e passa a exercer sua autoridade em ambientes impróprios, como sua casa ou entre amigos pessoais, pois acredita que em qualquer lugar sua palavra deve ser a última.

A inflação psíquica é um processo natural na consciência, promove o autoconhecimento, desenvolvimento de potencialidades, novas perspectivas sobre a realidade, favorecendo o processo de desenvolvimento psicológico ou individuação. Mas se torna patológica quando há alguma fraqueza na personalidade diante da autonomia dos conteúdos inconscientes, levando a uma possessão ou até identificação do eu com estes. (Jung, 2012d, §233).

Para Jung (2012e), a possessão é uma transformação subjetiva diferente da diminuição da personalidade (abaissement du niveau mental), pois o ego é tomado por um complexo autônomo. Diferente do abaissement que há uma diminuição da energia egoica, na possessão o ego-consciência está inflado, com a energia psíquica provinda do complexo inconsciente que a possui. A influência destes complexos dissociados da consciência podem ter efeitos agudos (passageiros, momentâneos no qual a personalidade do eu se transforma, como por exemplo, uma reação de medo) e crônicos (estáveis, de longa duração que modulam a personalidade, como por exemplo traumas, educação, etc).

Jung (2012e) define a possessão como uma mudança estrutural da subjetividade (§220). Há uma transformação na psicodinâmica do indivíduo quando está possuído por um complexo ou quando um arquétipo se constela. A pessoa torna-se obstinada, tomada por pensamentos, emoções, regras, ideais, formas de compreender e agir no mundo, planos e metas que é difícil de corrigir. Acrescenta que o núcleo de um complexo é um arquétipo, assim existe uma modulação e tendência típicas, na medida que determinados complexos constelam.

Isto significa que ser tomado pelo arquétipo da sombra leva a uma percepção negativa de si e da realidade, causa uma impressão desfavorável sobre os outros e experimenta o mundo com má sorte. Ser tomado pelo arquétipo de anima/animus leva a outras alterações na personalidade, adquirindo características do sexo oposto. Na mulher (que é tomada pelo animus) torna-se crítica, rígida, legalista, dogmática, entre outros. No homem (tomado pela anima) torna-se caprichoso, volúvel emocionalmente, descontrolado, mentiroso, etc. Também há outros processos de possessão dos complexos, de acordo com as qualidades arquetípicas. (Jung, 2012e).

Se por um lado, na inflação psíquica há um contato maior da consciência com o inconsciente, favorecendo a vulnerabilidade do ego pela possessão e identificação com um conteúdo inconsciente, por outro lado pode haver uma resposta negativa do ego-consciência perante o conteúdo inconsciente. O ego ao entrar em contato com a grande força energética dos complexos e das imagens primordiais, experimenta seus limites e vulnerabilidade e, por isso, se retrai e nega os conteúdos inconscientes (instintos, desejos, sentimentos e toda ordem de manifestação inconsciente). Jung denomina este fenômeno de restauração 
regressiva da persona, muito comum em casos pós-traumáticos. O que se observa é que, devido a uma experiência emocional intensa, o indivíduo busca viver uma vida aquém a sua real capacidade e potencialidade, esvaziada de criatividade e energia vital, assemelhando-se a quadros neuróticos. (Jung, 2012d).

Nos adoecimentos psíquicos, a consciência apresenta características regressivas, primitivas, infantis, arcaica. Isto se deve a emergência da função inferior na consciência. Ela é uma chave de ouro, pois é por ela que se acessa os conteúdos inconscientes, possuindo grande potencial de transformação da personalidade, assim como há um potencial destrutivo (psicopatológico).

Por tipos psicológicos compreende-se uma combinação entre as funções psicológicas do ego (sensação, intuição, sentimento e pensamento) com a disposição da libido (introvertida ou extrovertida). Para melhor compreensão dos tipos e direção da libido vide obra "Tipos Psicológicos" de Jung (2012f, p.344). A função inferior é a menos utilizada e desenvolvida, portanto a mais próxima do inconsciente. Normalmente, por meio dela que se acessa os conteúdos inconscientes. Cada tipo apresenta uma pré-disposição a determinados quadros psicopatológicos e não cabe aqui descrevê-los.

Jung (2013) afirma que a emergência dos conteúdos inconscientes na consciência cria uma tensão psíquica, pois algum conteúdo novo está para ser assimilado, e muitas vezes este é de natureza contraditória a consciência, como por exemplo, algum sentimento de raiva por pessoas que amamos. A situação de conflito psíquico é superada pela emergência de um símbolo, que é a representação da situação psíquica tal como ela é. Tem o intuito de promover uma síntese do conflito eu/consciente com o inconsciente, favorecendo uma nova perspectiva para a consciência. Porém, para que tal transcendência da situação conflituosa ocorra, é preciso que haja consciência das duas posições, de modo que o ego "suporte" (§94) a tensão sem desconsiderar ou reprimir qualquer conteúdo.

A necessidade de simbolizar é, portanto, segundo Jung (2012a), a necessidade de reconhecer os opostos por meio de uma relação dialética intermediada pelo ego, alcançar a síntese, "um deslocamento a partir da suspensão entre os opostos, e que leva a um novo nível de ser, a uma nova situação". (§189). Nos casos patológicos, a experiência não é simbolizada por não haver o reconhecimento do conflito, pois, ou foi reprimido na consciência ou o eu foi subjugado de alguma forma, tornando-se sintoma e não símbolo.

Dada a resistência do ego-consciência de flexibilizar sua atitude quando um conteúdo inconsciente entra em conflito, é possível afirmar que tais conflitos são de caráter moral e ético em sua essência. Eles desafiam o ego-consciência a confrontar seus próprios valores e ideais, reconhecendo o que foi reprimido, negligenciado, inferiorizado na consciência. Para Jung $(2014, \S 30)$ a moralidade é uma função da alma humana, é um regulador instintivo das ações, dos impulsos cuja finalidade é a adaptação gregária humana. Os princípios morais de uma sociedade são posteriores a esta função da alma, que agem naturalmente pela qualidade da necessidade.

Assim, é pela necessidade que se desenvolve a consciência e pela necessidade se reprime conteúdos psíquicos (impulsos, desejos, características 
pessoais, ideias, emoções), com finalidade adaptativa e de sobrevivência. A repressão se dá por meio de uma avaliação moral e ética, subjacente ao seu modo de interação e aos seus referenciais do mundo externo. $O$ que acontece é que estes conteúdos reprimidos permanecem inconscientes, mas ainda pertencem à totalidade da psique. (Jung, 2012a, §204).

O indivíduo tenta ser íntegro e adaptado socialmente com o custo da repressão, porém mente para si mesmo e não preserva a sua integridade psicológica. Isto gera outro tipo de tensão, um conflito com o Self ou Si Mesmo, a psique total. Parte do Self encontra-se reprimida e, por isto, o equilíbrio psíquico fica afetado, fazendo com que a energia estancada flua por outras vias formando sintomas, as psicopatologias. Assim, a integração do Self é realizada por questões morais e éticas, tanto com o mundo interno como externo.

Dentro de uma perspectiva mais ampla, a própria condição sócio-cultural do homem ocidental moderno favorece a inadaptação psicológica devido a falta de referenciais simbólicos que norteiam a vida psíquica dos indivíduos. A consciência do homem moderno é marcada pela supervalorização das funções racionais e lógicas em detrimento das funções irracionais como intuição, imaginação, sentimento. Para Jung $(2014, \S 150)$, existe uma função religiosa inata na psique que se manifesta simbolicamente na formação religiosa de todas as culturas. Com o advento do iluminismo, esta função religiosa e irracional passou a ser reprimida e relegada ao inconsciente devido a exacerbação do pensamento científicoracional. A postura racionalista unilateral da consciência moderna favoreceu para que a relação do homem com a natureza perdesse o caráter de integridade cósmica e religiosa, e passa a ser de investigação e dominação. (Jung, 2013, $\S 113)$.

A negligência da função irracional se dá pela falta de referenciais simbólicos (religiosos, mitológicos) que tem a função básica de ordenar e organizar a estrutura social, o cotidiano dos indivíduos e os fundamentos da alma. A consequência é que a energia psíquica volta-se para o inconsciente e a psique fica "intoxicada" com o excesso de libido, pois a função psíquica religiosa e irracional ficou reprimida no inconsciente. Daí, surgem os sintomas psicopatológicos (doenças que são deuses) e sociais (guerras, teorias sociais, políticas opressoras, etc). A falta de referenciais simbólicos corresponde a angústia de muitos neuróticos e de pessoas normais que se encontram sem "qualquer símbolo que ofereçam um caminho para a libido". (Jung, 2013, §342).

Os referenciais simbólicos auxiliam na orientação das etapas da vida humana, tais como nascimento, transição para puberdade, casamento, morte, etc. Trata-se de um movimento psíquico natural de transformação da personalidade que ocorre ao longo da vida. Jung $(2014, \S 114)$ descreve que a vida é como a trajetória do sol: há o nascer até o meio dia, que corresponde a primeira fase da vida, e do meio dia até o entardecer seria a segunda fase da vida.

Jung $(2012 b, \S 75)$ aponta para psicopatologias como dificuldades em atravessar etapas da vida: na primeira fase da vida, época de infância, juventude e início da fase da adulta, o individuo deveria estar construindo sua vida, por exemplo, casando, tendo filhos, construindo uma profissão, se adaptando ao meio 
externo. Mas em casos patológicos há um recuo ou hesitação diante do rumo a seguir. O indivíduo é invadido pelo medo de um desafio e então foge ou se esquiva de desenvolver suas potencialidades, restringindo sua atuação no mundo. Descreve este tipo de neurose como dependência anormal dos pais, criatividade deficiente por proposições e ambições inadequadas.

Já a neurose da segunda fase da vida corresponde a uma aproximação da realidade da morte e o velho recua adoecendo psicologicamente. Jung $(2014, \S 114)$ afirma que neste período existe um processo de transformação da personalidade denominada por metanóia. O indivíduo se depara com a necessidade de reconhecer o valor oposto aos antigos ideais, uma percepção transcendente do eu e da realidade. As funções menos desenvolvidas passam a ser requisitadas para desenvolver-se. Há uma relação mais evidente do eu com a totalidade do si mesmo. Acontecimentos como necessidade de mudar de emprego, de casamento, religião, é a prova desta inversão.

O problema está na repressão do que ficou pra traz ou então em resistir às mudanças de perspectivas. É importante que a consciência reconheça o valor das polaridades, compreenda que tudo que é humano é relativo.

\section{Considerações Finais}

Com referência aos temas levantados e discutidos acima, foi possível identificar algumas ideias centrais de Carl Gustav Jung a respeito das psicopatologias. Estas podem ser compreendidas como:

1. Repressão / Postura unilateral do ego - consciência;

2. Abaissement du niveau mental;

3. Possessão do ego-consciência por um complexo inconsciente;

4. Restauração Regressiva da Persona;

5. Emergência da função inferior na consciência;

6. Experiência não simbolizada;

7. Contradição ética e moral da personalidade;

8. Ausência de referenciais simbólicos no contexto sócio-cultural;

9. Dificuldade de atravessar etapas da vida.

Não se trata de elaborar uma sistematização teórica nem uma definição conceitual fechada sobre psicopatologia, mas sim de discriminar e organizar estas ideias. Para Jung, as teorias são instrumentos para o conhecimento e terapia, auxiliam aprofundar-se na compreensão das múltiplas faces da alma humana.

Os resultados da pesquisa corroboram com os sete itens elencados de Samuels (1989, p.86) no levantamento bibliográfico deste artigo. De modo geral, trata-se de "Psicopatologias do Ego", conforme este autor cita, devido ao contato com as imagens arquetípicas e a incapacidade deste de se adaptar ao meio. A 
relação ego-inconsciente encontra-se defasada nas psicopatologias, causando os "desequilíbrios mentais".

A ideia de "equilíbrio mental" parece ser o que mais se aproxima da noção de saúde mental na Psicologia Analítica de Jung. O equilíbrio se dá pela relação de alteridade entre a consciência e o inconsciente, no qual o ego concilia as demandas externas e internas sem se identificar com as imagens coletivas, tanto sociais como arquetípicas. A relação de alteridade significa que o ego reconhece as demandas internas e externas, de modo a buscar uma adaptação ideal, que sempre é de qualidade individual, posto que a adaptação varia de caso para caso.

Assim, o ego assume um papel de mediador destas demandas e o adoecimento psíquico sempre se dá pela sua impossibilidade de alcançar um estado adaptado com sua realidade interna e externa devido a uma fragilidade. Jung não se propõe a investigar sobre o "por quê?" da fragilidade egóica nas psicopatologias. Para ele, o método redutivo-causal (psicanalítico, de investigar as causas do adoecimento psíquico) limita a perspectiva compreensiva-simbólica. Como foi dito anteriormente, desenvolve a método hermenêutico sintético ou construtivo para compreender os fenômenos psicológicos e encontrar uma finalidade teleológica do adoecimento. Esta perspectiva finalista leva ao entendimento de que as doenças podem favorecer o desenvolvimento da personalidade ou individuação por meio da elaboração simbólica. Busca, então, responder o "para quê?" dos adoecimentos psíquicos.

A perspectiva simbólica desenvolvida por Jung encontra nos mitos as expressões simbólicas máximas da psique, são revelações do desenvolvimento dramático significativo que refletem condições essencialmente humanas e universais, fazendo com que o drama particular do individuo contemporâneo possa ser compreendido e incorporado a um tema típico humano. A manifestação de padrões de comportamentos, emoções, ideias estereotipadas das psicopatologias são descritas como uma "inflação psíquica", onde há um estado de "semelhança a Deus”. (Jung, 2012d, §224).

A perspectiva psicogênica e simbólica de Jung eleva a compreensão dos fenômenos psicopatológicos para além da materialidade fisiológica do humano, e direciona para o presente e futuro, identificando sentido e finalidade no adoecimento psíquico. A prática da psiquiatria convencional, com seu avanço nas neurociências e na genética, parece estar distanciada das perspectivas mais compreensivas. Muito a psicologia já avançou e trata-se de um retrocesso quando se observa o excesso de medicação, a falta de diálogo e vínculo entre paciente e médico, a compreensão dos fenômenos psíquicos como sintomas e anormalidade. O problema essencial desta perspectiva médica é o distanciamento do homem com sua alma, com sua subjetividade e com sua história. 


\section{Referências}

Clarke, J. J. (1993). Em busca de Jung. Rio de Janeiro: Ediouro.

Delgalarrondo, P. (2008). Psicopatologia e semiologia dos transtornos mentais. Campinas-SP: Artmed.

Ellemberger, H.F. (1976). El descubrimiento del inconsciente: historia y evolución de la psiquiatria dinâmica. Madrid: Editorial Gredos.

Fierz, H.K. (2007). Psiquiatria Junguiana. São Paulo: Paulus; 2007.

Hart, D.L. (2002). A escola junguiana clássica. In: Young-Eisendrath, P.; Dawson, T. (Org.) Manual de Cambridge para Estudos Junguianos.(Ed.1, pp. 101-110). Porto Alegre-RGS: Artmed Editora.

Himiob, G. (2006). Esquizofrenia y otros transtornos psicóticos. In: Laureiro M.E.S. (Org.) Psicopatologia psicodinâmica simbólicoarquetípica: uma perspectiva junguiana de integración em psicopatologia y clínica analítica. (Vol.1, pp.219-238). Montevideo: Prensa Médica Latinoamericana.

Jung, C.G. (2012a). A natureza da psique.(10 $0^{\mathrm{a}}$ ed.). Petrópolis-RJ: Vozes.

Jung, C.G. (2012b). A prática da psicoterapia.(15a ed.). Petrópolis - RJ: Vozes.

Jung, C.G. (2012c). A psicogênese das doenças mentais. (6 $6^{\underline{a}}$ ed.). Petrópolis-RJ: Vozes.

Jung, C.G. (2012d). O eu e o inconsciente. (24를 ed.). Petrópolis-RJ: Vozes.

Jung, C.G. (2012e). Os arquétipos e o inconsciente coletivo. (9 ${ }^{a}$ ed.). Petrópolis - RJ: Vozes.

Jung, C.G. (2012f). Tipos Psicológicos. (6ª ed.). Petrópolis-RJ: Vozes.

Jung, C.G. (2013). Símbolos da transformação: análise dos prelúdios de uma esquizofrenia. (9 $9^{a}$ ed.). Petrópolis-RJ: Vozes.

Jung, C.G. (2014). Psicologia do inconsciente. (24를 ed.) Petrópolis, Vozes.

Martinez, J.R. (2006). Metapsicopatologia da Psiquiatria: Uma Reflexão sobre o Dualismo Epistemológico da Psiquiatria Clínica entre a Organogênese e a Psicogênese dos Transtornos Mentais. Tese de 
Doutorado não publicada, Universidade Federal de São Carlos, São Carlos - SP, Brasil.

Samuels, A. (1989). Jung e os pós-junguianos. Rio de Janeiro: Imago.

Samuels, A. (2002). Psychopathology: contemporary Junguian perspectives. London: Karnac.

Serbena, Carlos Augusto; Zanoni, Anna Paula. (2011). A psicopatologia como experiência da alma. Revista latino-americana de psicopatologia fundamental, São Paulo, vol.14, n.3.

Shandasami, S. (2011). Jung e a Construção de uma Psicologia Moderna: O Sonho de uma Ciência. Aparecida-SP: Editora Idéias e Letras. 